Chapter 6

\title{
Fruit Tree Pollination Technology and Industrialization in China
}

\author{
Guo Yuan, Ma Weihua, Wu Wenqing and \\ Song Huailei \\ Additional information is available at the end of the chapter \\ http://dx.doi.org/10.5772/62854
}

\begin{abstract}
This work investigates the bee pollination of fruit trees, especially apples and pears in the field. We first introduce research carried out into bee pollination of crops in China, and then our own pollination experiments with managed bees such as Apis mellifera in the field. We monitor the efficiency of bee pollination of fruit trees by regulating hive bees and tree arrangement. In addition, we develop some methods to attract bees to visit fruit trees. Our research shows that thenumber of beehives and the arrangement of trees greatly influence bee pollination. The results provide a comprehensive tutorial on the best practices of bee pollination of fruit trees.
\end{abstract}

Keywords: Bees, pollination, fruit tree, apples, pears, pollination efficiency

\section{Introduction}

About $75 \%$ of all crops require pollination by bees. Some pollination is done by domesticated honeybees, but the pollination of most crops is done by wild insects, including wild bees. The decline of wild bee diversity in China has forced farmers to depend on managed bees such as Apis mellifera. The most prominent example can be found in southwest China where the cultivated area devoted to apple and pear trees is being expanded year by year, but at the cost of decrease in the number of wild pollinators because of environmental degradation, air pollution, pesticide usage, and so on. This means that crops cannot get sufficient pollination. Those places where there is a serious shortage of pollinators even make use of manpow- 
er to replace insect pollination, which increases the cost of production dramatically. To reduce the cost of pollination and improve the efficiency of pollination, this study looks at how best to get bees to pollinate apple and pear trees, including such factors as how to attract bees to pollinate, selection of optimum bee species, and optimum bee configuration. The work provides a basis for the application of bee pollination technology for crops.

\section{Pollination problem facing development of the fruit industry in China}

\subsection{Development of the fruit industry}

China is a large country with many natural habitats and rich fruit tree resources. The cultivation of fruit trees involves more than 50 families of fruit trees, more than 300 species, and more than 10,000 varieties. Principal among these are apple, pear, peach, plum, apricot, plum, grapes, cherry, walnuts, citrus fruit, lychee, longan, loquat, olives, kiwi fruit, fig, pomegranate, Phyllanthus emblica (Indian gooseberry), banana, pineapple, durian, mangosteen, breadfruit, cocoa, and betel nuts, the majority of which are widely distributed throughout China. The area devoted to fruit cultivation and fruit yield are among the highest in the world.

Apple trees have a wide distribution in China, can be evergreen or deciduous, and are widely grown across the Yunnan-Guizhou plateau. The deciduous varieties can be broken down into temperate deciduous, deciduous with dry temperature, dry cold deciduous, and hardy deciduous (figure 1) ${ }^{[1]}$. In 2011 the cultivated area devoted to apples in China reached 2.177 million $\mathrm{hm}^{2}$, accounted for about $42.0 \%$ of the world's total area devoted to the cultivation of apple, total output reached 35.985 million $t$, represented about $54.2 \%$ of total world yield, and had an output value of 160.52 billion yuan ${ }^{[2]}$.

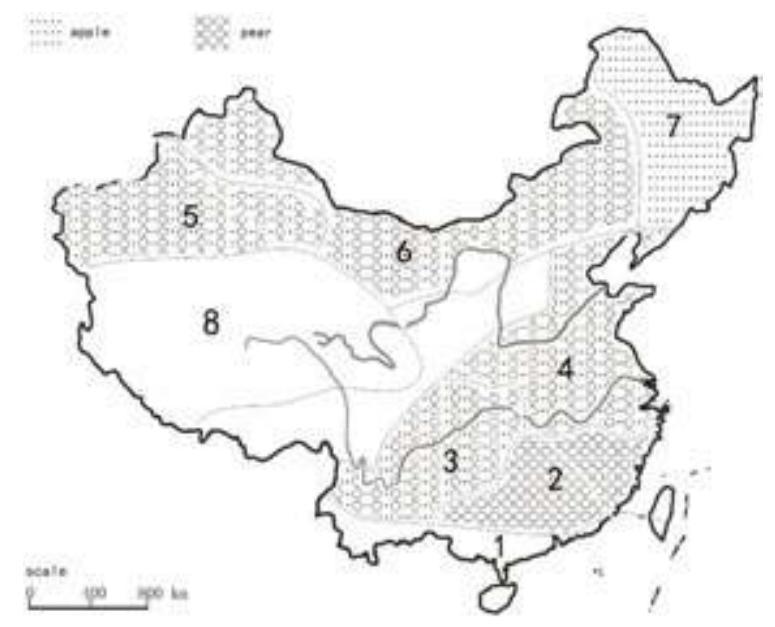

Figure 1. Distribution of fruit trees in China. 
Pear trees are also important; they are grown across five fruit zones. They too can be deciduous or evergreen. Subtropical evergreen trees are grown in the south, whereas cold and dry deciduous fruit trees are grown in the north ${ }^{[1]}$ (figure 1). By the end of 2012, according to statistical data released by the United Nations Food and Agriculture Organization ${ }^{[3]}$, China's harvest pear covers an area of 1.138 million $\mathrm{hm}^{2}$, production is 1.721 million $\mathrm{t}$, and area and yield are among the highest in the world.

Peach trees grow in temperate areas of China. They are mainly distributed in the YunnanGuizhou Plateau. They too can be evergreen or deciduous. They can be broken down into evergreen and deciduous mixed, temperate deciduous, dry-temperature deciduous (figure 1) ${ }^{[1]}$. According to statistical data published by the United Nations Food and Agriculture Organization ${ }^{[3]}$ by the end of 2010 the area devoted to peach cultivation in China was 732,000 $\mathrm{hm}^{2}$ and yield reached 10.828 million $\mathrm{t}$, both of which were the highest in the world.

Fruit production has made great progress in China in recent years. This mainly applies to producing larger varieties, breeding, developing good fruit quality, and marketing of popular market varieties. The biological characteristics of tree species, their adaptability to the environment, improvement of plant varieties, and growing stock in the most appropriate biome possible, all help to optimize efficiency ${ }^{[4,5]}$ and improve fruit market competitiveness and economic benefits.

\subsection{Serious shortage of fruit tree pollinators}

Most of the apple, pear, plum, apricot, and chestnut varieties as well as almost all the sweet cherry varieties need be cross-pollinated for the production of seed ${ }^{[6]}$. Because the pollen grains of nuts and fruits are big, heavy, sticky, and have an outer wall with a pattern of bumps, the wind cannot spread them easily. These fruits rely mainly on insect pollination, especially bees $^{[7,8]}$.

According to a survey of the literature, in the major apple-producing areas in Shanxi Province a total of 23 species of insects visit apple flowers. They belong to 4 orders and 14 families, mainly comprising hymenopteran (Hymenoptera) bees (Apidae), an anthophorid bee (Anthophoridae), leafcutting bees (Megachilidae), an andrenid bee (Andrenidae), and a dipteran (Diptera, Syrphidae). Among them, the Italian bee (Apis mellifera ligustica), which accounts for 61.5 to $99.4 \%$ of pollinators, is the apple's main pollinator. The foraging peaks of the Italian bee and Anthophora plumipes (Pallas, 1772), another local pollinator known as the hairy-footed flower bee, stagger, reducing competition between each other ${ }^{[9]}$. Lu Yanguo et al. visited insectpollinated apple blossom in central and southern loess plateau regions. The results show that the bee is the main pollinator in Tianshui and Liangdi, where it accounted for 92.6 and $60 \%$, respectively, of all insect pollination ${ }^{[10]}$. Yang and $\mathrm{Wu}$ surveyed the number and species of insects pollinating kiwi fruit flowers. They identified 16 species of pollinator, including bees (11), food aphid flies (4), and a dung beetle (1). Statistical analysis of the pollination behavior and pollination frequency showed that the bee Apis cerana cerana and the Italian bee are the best pollinators, with other insects much less active, carrying less pollen, and having much less of an impact ${ }^{[11]}$. Zhang Yunyi et al. investigated species of pollinators and the quantity of large cherry trees in Shanxi, and found that hymenopterans accounted for 64.83 to $74.81 \%$ of 
the pollinators. Hymenopteran pollinators are the most important. Interestingly, pollinators in mountainous area are richer in species than those in the plain ${ }^{[12]}$.

In recent years the number of bees and other pollinators has fallen sharply, which has drawn wide attention across the world. It is likely due to the use of pesticides resulting in a significant decline in the number of wild pollinators ${ }^{[13,14]}$. In addition, large-scale clearing of land for farming in the 15th and 16th centuries led to serious restriction of the habitat of wild insects. Climate change may cause inconsistency in plant phenophases and pollinator development periods, resulting in inadequate pollination ${ }^{[17]}$. In short, fruit tree pollination is the most pressing problem, with artificial pollination having to be adopted in some areas (figure 2); for example, about $30 \%$ of China's pear trees are artificially pollinated ${ }^{[18]}$.

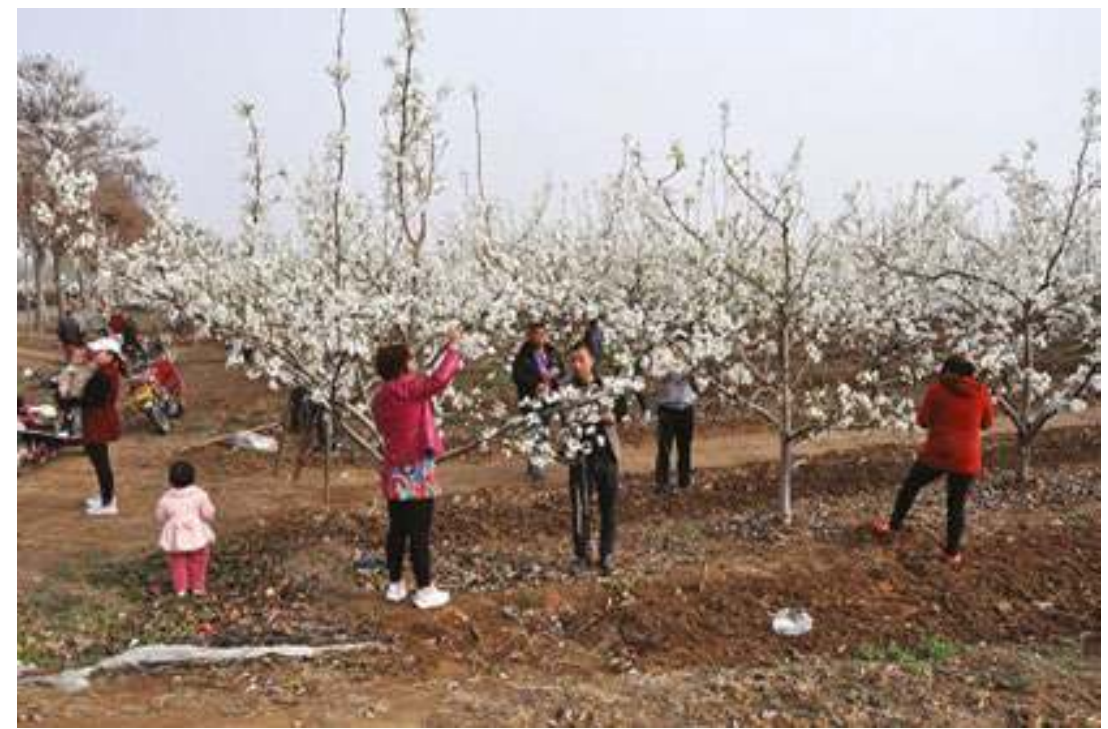

Figure 2. Artificial pollination.

\section{Present situation of fruit industry pollination technology in China}

\subsection{Chinese institutions engaged in research on fruit tree pollination technology}

Chinese literature from 1980 to 2013 reveals that there are 161 institutions engaged in fruit tree pollination research, principal among which are the Chinese Academy of Agricultural Sciences' Institute of Bees, the Horticulture Institute of the Shanxi Academy of Agricultural Sciences, and the Beijing Academy of Agriculture and Forestry. Between 1980 and 2011, there were 324 research papers on bees pollinating trees (figure 3), including 66 articles written between 1980 and 1992 (an average of 5 articles per year), a relatively stable number of articles 
between 1993 and 2001, and 204 articles from 2001 to 2011. Research content covered a wide range of factors from bee pollination methods, bee species selection to effects on cultivation and pollination evaluation. There were a few papers looking into how bee pollination increases production, bee pollination and ecology, crop breeding, and pollination colony management (figure 4).

Figure 3. Literature about bee pollination from 1980 to 2011.

Figure 4. Bee pollination literature by research content. 
Between 2001 and 2011, nine books were published on insect pollination technology research and application (table 1).

\begin{tabular}{|c|c|c|c|c|}
\hline Monograph title & Author & Publishi & ePress & Page \\
\hline $\begin{array}{l}\text { Technology of Bee Breeding and } \\
\text { Pollination }\end{array}$ & Zeng Zhijiang & 2001.07 & $\begin{array}{l}\text { Shanghai Popular Science } \\
\text { Press }\end{array}$ & 274 \\
\hline Bee Pollination & Shao Youquan & 2001.09 & $\begin{array}{l}\text { Shanxi Science and } \\
\text { Technology Press }\end{array}$ & 113 \\
\hline $\begin{array}{l}\text { New Technology of } \\
\text { Osmia Pollination for Fruit Tree }\end{array}$ & Zhou Weiru & 2002.01 & Jindun Press & 143 \\
\hline $\begin{array}{l}\text { Pollination Insect } \\
\text { and Technology of Pollination }\end{array}$ & Wu Jie & 2004.01 & $\begin{array}{l}\text { Chinese Agric } \\
\text { ulture Press }\end{array}$ & 204 \\
\hline Bee Pollination Handbook & $\begin{array}{l}\text { Zhang Zhongyin, An } \\
\text { Jiandong, Luo Shudong } \\
\text { et al. }\end{array}$ & 2008.10 & $\begin{array}{l}\text { Chinese Agri } \\
\text { culture Press }\end{array}$ & 93 \\
\hline Apiculture and Ecology & Wang Yong & 2009.05 & $\begin{array}{l}\text { Chinese Agriculture } \\
\text { Science and } \\
\text { Technology Press }\end{array}$ & 127 \\
\hline $\begin{array}{l}\text { Yield Increasing } \\
\text { Techniques of Insect } \\
\text { Pollination for Fruit } \\
\text { and Vegetable }\end{array}$ & $\begin{array}{l}\text { Shao Youquan, Qi } \\
\text { Haiping }\end{array}$ & 2010.05 & Jindun Press & 202 \\
\hline $\begin{array}{l}\text { Bumblebee Artificial } \\
\text { Propagation and } \\
\text { Pollination }\end{array}$ & $\begin{array}{l}\text { Liu Xinyu, Gao } \\
\text { Chongdong }\end{array}$ & 2011.05 & $\begin{array}{l}\text { Northwest Agric } \\
\text { ulture and Forestry } \\
\text { University } \\
\text { Press }\end{array}$ & 133 \\
\hline $\begin{array}{l}\text { Technique of Crop } \\
\text { Yield Increasing: Bee } \\
\text { Pollination }\end{array}$ & Wu Jie, Shao Youquan & 2011.07 & Chinese agriculture press & 173 \\
\hline
\end{tabular}

Table 1. Monographs on bee pollination in China.

According to the State Intellectual Property Office patent database, from 2000 to 2013 there were 54 classes of bee pollination patents: 43 invention patents and 11 utility model patents. They covered a wide range of factors from bee pollination application technology, pollinating bee breeding technology, pollinating bee management methods, to the induction of bee pollination methods, design and transformation of pollination hives, and bee pollination control devices. Patentees came from a number of provinces and cities, with Beijing, Zhejiang, and Shandong ranking in the top three. Between 2000 and 2007 a total of 15 patents were 
granted, and between 2008 and 2013 the total was 39. Patents related to bee pollination are clearly on the increase.

From the National Network of Scientific and Technological Achievements we retrieved 41 classes of bee pollination, principal among which were 17 classes on bee species breeding and selection accounting for $41.5 \%$ of total results. In addition, there were classes covering bee application and technology research (14), beehive design (2), and pollinating bee species resources (3). The results show that of the pollinating bees-bumblebees, osmia bees, and leafcutters-bumblebee research was the most impotant. From the point of view of achievements, institutes in Beijing, Jilin, and Shanxi were in the top three. Regarding the number of achievements the Beijing Forestry Academy of Sciences, the Chinese Academy of Agricultural Sciences' Institute of Bees, and the Horticulture Institute of the Shanxi Academy of Agricultural Sciences were in the top three. The Beijing Academy of Agriculture and Forestry made great progress in providing facilities for crop pollination, bee species breeding, utilization, demonstration, and pollination hive development. The Chinese Academy of Agricultural Sciences' Institute of Bees made a breakthrough in bumblebee breeding, utilization, and application. The Horticulture Institution of the Shanxi Academy of Agricultural Sciences had a lot of success as a result of providing improved facilities for vegetable production technology research and application.

\subsection{Effectiveness evaluation of bee pollination for fruit trees}

After the bee Osmia cornifrons (Ra doszkowski) was imported by the Biological Control Research Institute of the Chinese Academy of Agricultural Sciences from Japan in 1987 the pollination effectiveness of the fruit-setting rate and fruit quality of apricot, cherry, peach, pear, and apple in Hebei and Shandong were remarkable.

After using Apis mellifera ligustica for apple pollination, Zhang Guiqian et al. found that, compared with natural pollination, bee pollination increased the "Red Fuji" apple fruit yield by $46.8 \%$, reduced the misshapen fruit rate by $22.4 \%$, and increased yield to $14,124 \mathrm{~kg} / \mathrm{hm}^{2}[20]$. He Weizhi and Zhou Weiru researched the use of the concave-lipped bee Osmia excavata Alfken, the Italian bee, and artificial pollination for "Red Fuji" apple pollination. The results showed the apple fruit yield of the six kinds of pollination was significantly higher than that of natural pollination; the pollination effect of osmia bees combined with Italian bees was best with a high inflorescence fruit rate of $99.6 \%{ }^{[21]}$. Lou Delong et al. found that the "Red Fuji" apple fruit yield, production, and coloring index of bee pollination were higher than those of natural pollination by $15,36.26$, and $17.07 \%$, respectively ${ }^{[22]}$. Using bee pollination for apple and pear, Zhao Zhonghua et al. found that fruit yield was more than $20 \%$ higher than artificial pollination and the average production of each acre was $224.4 \mathrm{~kg}, 335.3 \mathrm{~kg}$ with the increase rate of $8.7 \%$ and $11.3 \%{ }^{[23]}$. Yuan Feng et al. used osmia bees and honeybees to pollinate "Red Fuji" apple trees and found that fruit yield increased by 14.68 and $10.95 \%$, respectively, over the natural pollination yield and the fruit abscission rate reduced by 32.9 and $20.27 \%$, respectively ${ }^{[24]}$.

In addition, the effect of using a variety of bees for pear and peach pollination was clear. Liu Jinli et al. increased the fruit yield of crown pears, emerald pears, south fruit pears, and gold 
pears by using concave-lipped osmia for pollination by 11 to $18.4 \%$ compared with that of artificial pollination ${ }^{[25]}$. Guo Yuan et al. researched different pollination methods for pear and found that the fruit yield of bee pollination was 32.9\%, artificial pollination $13.05 \%$, and natural pollination only $2.83 \%{ }^{[26]}$. Dong Jie et al. used Italian bees and Bombus hypocrita to pollinate peach trees; the results showed that any difference in peach fruit yield and fruit nutritional quality of the two kinds of bee pollination was not significant and that both were significantly better than that of artificial pollination ${ }^{[27]}$. Mu Hongjie used bumblebees and bees to pollinate fruit trees; the results showed that the fruit yield of bumblebee pollination was higher than that of bee pollination, with an increase of $25.5 \%$ in the nectarine yield ${ }^{[28]}$. Means within a column followed by the different letters are extremely significant different at P 0.01 level.

From 2008 to 2015, researchers from the Horticultural Institute of the Shanxi Academy of Agricultural Sciences carried out research into bee pollination for the "Red Fuji" apple; the results show that bees can significantly improve the fruit-setting rate (table 2 ).

\begin{tabular}{lllll}
\hline Variety & Pollination pattern & Flower number & Fruit number & Fruit-setting rate (\%) \\
\hline “Red Fuji" & Bee & 1004 & 240 & 23.9 \\
& Nature & 1044 & 96 & 9.2 \\
“Starkrimson" & Bee & 1258 & 438 & 34.8 \\
& Nature & 1098 & 93 & 8.5 \\
\hline
\end{tabular}

Table 2. Fruit-setting rate by bee and natural pollination.

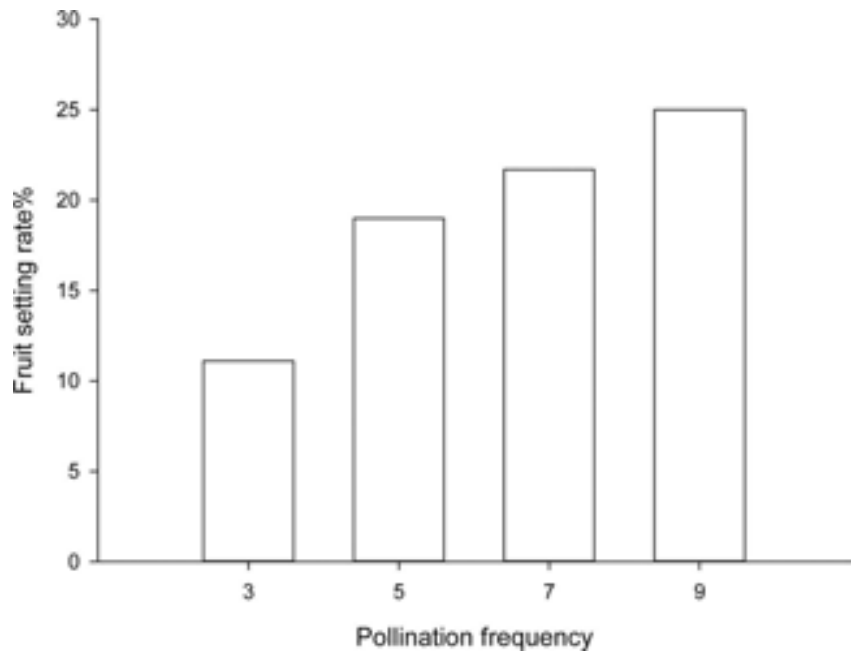

Figure 5. Fruit-setting rate by number of pollination visits. 
In addition, three, five, seven, and nine lots of bee pollination resulted in increased fruit yield to the tune of $11.1,19,21.7$, and $25 \%$, respectively, as shown in figure 5 . So the greater the number of visits made by bees to pollinate the higher the fruit yield.

Bee pollination stimulates the growth of young fruit. The average yield of each tree after bee pollination was $69.8 \mathrm{~kg}$ compared with $31.9 \mathrm{~kg}$ of natural pollination. The fruit shape index of bee pollination and natural pollination were similar, but the coloring index of bee pollination was significantly better than the natural pollination group; the results are shown in table 3 .

\begin{tabular}{llllll}
\hline Pollination pattern & Fruit shape index & Color index (\%) & Chemical quality & & \\
\cline { 3 - 6 } & & & Solid content (\%) & Acidity (\%) & TSS:acid ratio \\
\hline Bee & 0.8282 & 67.33 & $13.53 \pm 1.63 \mathrm{~A}$ & $0.34 \pm 0.05 \mathrm{~B}$ & $40.98 \mathrm{~A}$ \\
Nature & 0.8516 & 47.33 & $13.93 \pm 1.34 \mathrm{~A}$ & $0.43 \pm 0.07 \mathrm{~A}$ & $32.71 \mathrm{~B}$ \\
\hline
\end{tabular}

Notes: Fruit shape index: The ratio of longitudinal diameter to transverse diameter. Color index $=\Sigma$ (Fruit number of each class $\times$ Extreme value)/(Total fruit number $\times$ The highest series $) \times 100 \%$. TSS, total soluble solids.

Table 3. Different pollination patterns.

\subsection{Key technology underlying bee pollination of apples and pears}

\subsubsection{Configuration of pollination trees}

About 70\% of trees under production in orchards in Shanxi receive insufficient or no pollination. We have researched the ratio between pollination partners and the cultivation of fruit trees. In some pear gardens, pollination branch grafting guarantees bee pollination. Research shows that self-incompatibility occurs when pear trees have the same S-type genotypes, hence cultivation of at least one $S$ genotype of different varieties as pollination partners should be undertaken. Table 4 outlines the main culture of some varieties and their appropriate pollination partners.

\begin{tabular}{ll}
\hline Main varieties & Pollination partners \\
\hline Pyris pyrifolia Nak. cuiguang & $\begin{array}{l}\text { P. pyrifolia Nak. qingxiang, huanghua } \\
\text { Pyris bretschneideri Rehd. huangguang, xinya }\end{array}$ \\
P. pyrifolia Nak. xizilv & P. bretschneideri Rehd. zaosu, hangqing \\
& P. bretschneideri Rehd. zhongliyihao \\
P. bretschneideri Rehd. huan & jimi, P. bretschneideri Rehd. zhongliyihao, fengshui \\
gguang & xianhuang, fengshui, huanghua, xueqing \\
yuanhuang & huanghua, xinshui, P. bretschneideri Rehd. \\
fengshui & dangshansu, P. bretschneideri Rehd. huangguang
\end{tabular}




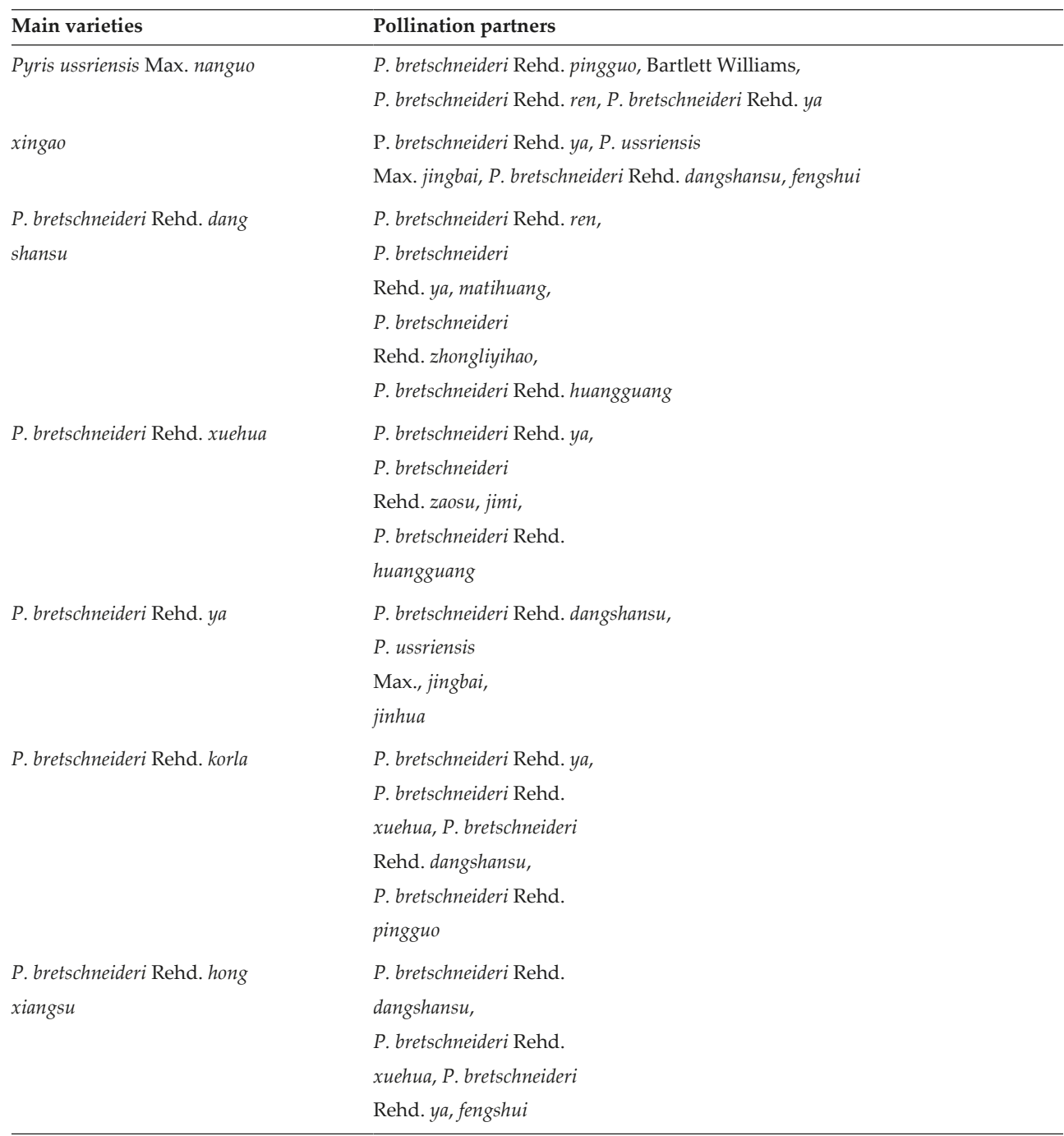

Table 4. Configuration of main pear variety and appropriate pollination partners in Shanxi.

The ratio between pollination partners and the main variety can be 1:4-1:8; 1:6 has been found to be optimal. To ensure full pollination and prevent flowering inconsistency the main variety should be paired with two pollination partners; namely, six main varieties and one pollination variety.

In addition, we can increase the supply of pollen by means of grafting pollination branches (figure 6). 


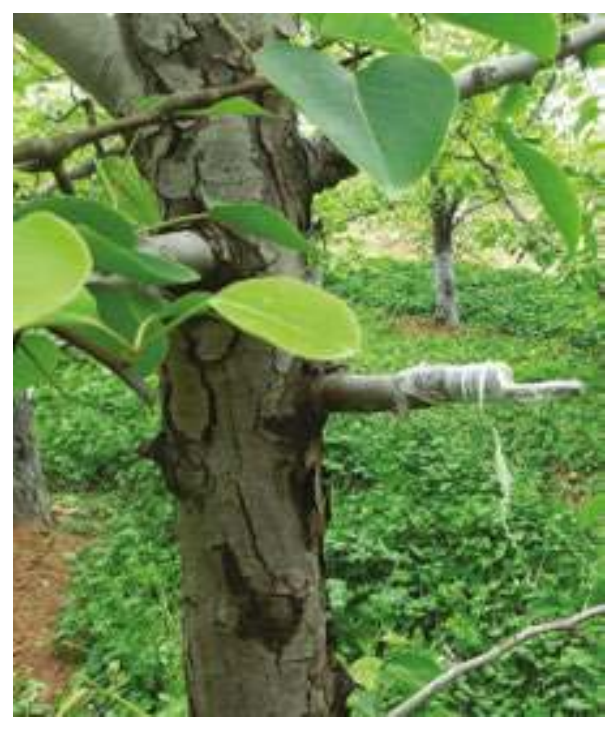

Figure 6. Central branch grafting of pear pollination partners.

\subsubsection{Selection of pollinating bee species}

Apis mellifera cv. "Kaqian Black Ring Bee", Apis mellifera cv. "Mr. Northeast Black Bee", Apis mellifera caucasica, Apis mellifera cv. "Honey-proplis 1 Bee", Apis mellifera cv. "Carpathian Bee", Apis mellifera cv. "Heimeiyi", Apis mellifera carnica, the Italian bee, and Apis cerana cerana

Figure 7. Temperature of outflying and backflying bee varieties. 
Fabricius were usually used for pollination. However, the nine varieties differ in their life habits (figure 7), their ability to carry pollen (figure 8), and their collection of pear flower powder proportion (figure 9). Therefore, in the process of pollination we need to choose appropriate bees for pollination according to different fruit trees.

Figure 7 shows that the outflying temperature of Apis cerana cerana Fabricius was $8.2^{\circ} \mathrm{C}$, which was significantly lower than western bees $\left(9.2-10^{\circ} \mathrm{C}\right)$. Apis mellifera carnica can fly out of the nest at $9.2^{\circ} \mathrm{C}$; there were no significant differences among western bees. The average backflying temperature of all bee species was $12.1^{\circ} \mathrm{C}$ and the average pollen-carrying temperature of Apis mellifera cv. "Kaqian Black Ring Bee", Apis mellifera cv. "Northeast Black Bee", Apis mellifera cv. "Honey-proplis 1 Bee", Apis mellifera carnica, and Apis cerana cerana Fabricius was significantly lower than Apis mellifera caucasica and the Italian bee.

The weight of total pollen and pear pollen collected by bees in one hour was compared and analyzed (figure 8). Apis mellifera carnica collected more pollen than the others, and Apis cerana cerana Fabricius collected the least. Apis mellifera cv. "Kaqian Black Ring Bee" collected the most pear pollen in one hour and Apis mellifera cv. "Honey-proplis 1 Bee" and Apis cerana cerana Fabricius collected the least pear pollen. Apis mellifera cv. "Kaqian Black Ring Bee" and Apis mellifera carnica were much the same but they both collected more pear pollen than the others. They can collect five times more pear pollen than Apis cerana cerana Fabricius.

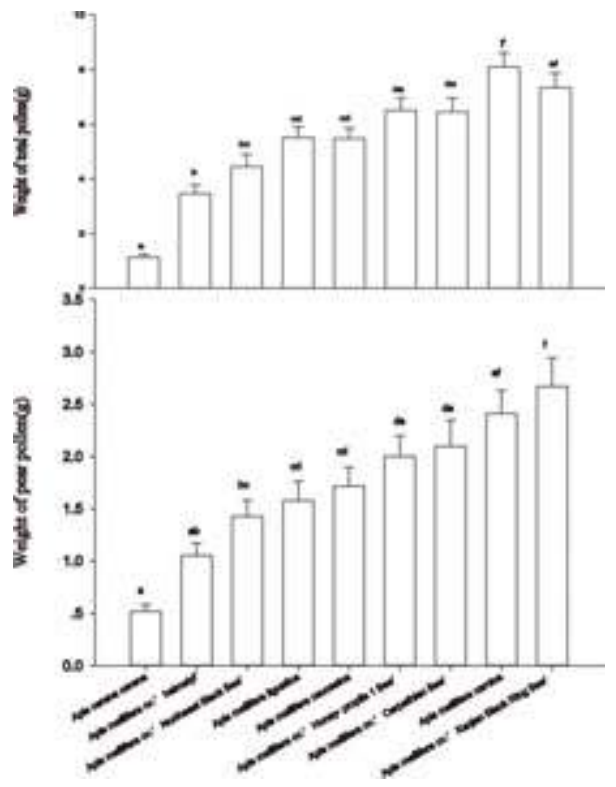

Figure 8. Total pollen and pear pollen collected by different bee varieties in one hour. 
The proportion of pear pollen collected by Apis mellifera carnica was highest (45.2\%) and Apis mellifera cv. "Kaqian Black Ring Bee" was the second highest (42.4\%). Nevertheless, there was no significant difference among the species (figure 9).

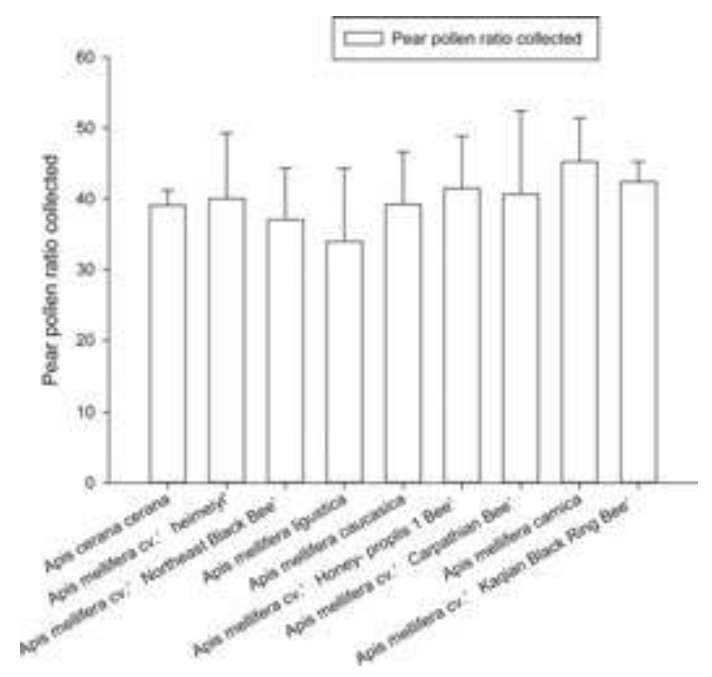

Figure 9. Pear pollen collected by different bee varieties.

Since pear trees bloom throughout China at different times, there is a need for pollinating bees that are not only good at pollen collection but adapt well to the environment. Pear trees flower early when the temperature is low, so bees have little choice but to pollinate pear trees in low temperatures. Of the nine species of bees selected, Apis mellifera cv. "Kaqian Black Ring Bee" and Apis mellifera carnica adapted best to the environment and were best at collecting pollen, especially pear pollen. So they can be recommended to pollinate pear trees.

\subsubsection{Control of pollination bees}

Insect pollination can be used to improve the fruit-bearing rate and yield, but it does not follow that the higher the fruit-bearing rate the better the yield. If the fruit-bearing rate is too high, nutrients will be depleted resulting in small-sized fruit and poor yield. Therefore, the key technical problem is to adjust the number of bees to control the fruit-setting rate.

Table 5 shows that the greater the varieties of bees the greater the subsidence on stigma pollen, the higher the fruit-setting rate, and the greater the yield. The fruit-setting rate is low with one to four varieties of bees; however, when the varieties of bees are increased to six or eight there could be an increase to 9.6 or $17.9 \%$, respectively. In addition, using different varieties of pollination bees can also affect the quality of apples (table 6). When six varieties of pollination bees were employed the fruit not only met the appropriate requirements but tasted good too. All in all, when the ratio between pollination partners and main varieties is 1:4, each tree can meet production requirements with six bees. 


\begin{tabular}{llll}
\hline Number of bee varieties used & Pollen amount on stigma & Fruit-setting rate (\%) & Average yield/each tree $(\mathbf{k g})$ \\
\hline $\mathbf{1}$ & 678.52 & 2.87 & $\mathbf{6 5 . 7 5}$ \\
$\mathbf{2}$ & 832.08 & 3.07 & $\mathbf{6 5 . 5}$ \\
$\mathbf{4}$ & $1,112.9$ & 3.31 & $\mathbf{6 6 . 5}$ \\
$\mathbf{6}$ & $1,145.8$ & 9.63 & $\mathbf{7 9 . 2 5}$ \\
$\mathbf{8}$ & $\mathbf{1 , 3 6 0 . 4}$ & $\mathbf{1 7 . 8 7}$ & $\mathbf{1 1 9 . 2 5}$ \\
\hline
\end{tabular}

Notes: Experiments were conducted in net houses. The ratio between pollination partners and main varieties is 1:4.

Table 5. Stigma pollen count, fruit-setting rate, and yield employing different numbers of varieties of pollination bees.

\begin{tabular}{lllllll}
\hline $\begin{array}{l}\text { Number of bee } \\
\text { varieties used }\end{array}$ & $\begin{array}{l}\text { Soluble solids } \\
\mathbf{( \% )}\end{array}$ & Acid $\mathbf{( \% )}$ & $\begin{array}{l}\text { Hardiness in the sun Hardiness in the } \\
\left(\mathbf{N} / \mathbf{c m}^{2}\right)\end{array}$ & $\begin{array}{l}\text { Fruit shape } \\
\text { index } \\
\left(\mathbf{N} / \mathbf{c m}^{2}\right)\end{array}$ & $\begin{array}{l}\text { TSS-acid } \\
\text { ratio }\end{array}$ \\
\hline 1 & $15.0527 \mathrm{bc}$ & $0.302 \mathrm{~d}$ & $9.154 \mathrm{~b}$ & $9.24 \mathrm{~b}$ & 86.44 & 49.79 \\
2 & $14.8423 \mathrm{c}$ & $0.318 \mathrm{~cd}$ & $10.809 \mathrm{a}$ & $10.72 \mathrm{a}$ & 87.81 & 46.7 \\
4 & $15.9480 \mathrm{ab}$ & $0.3906 \mathrm{~b}$ & $10.509 \mathrm{a}$ & $10.23 \mathrm{a}$ & 86.96 & 40.82 \\
6 & $16.6893 \mathrm{a}$ & $0.502 \mathrm{a}$ & $10.46 \mathrm{a}$ & $10.31 \mathrm{a}$ & 88.49 & 33.25 \\
8 & $15.6733 \mathrm{bc}$ & $0.375 \mathrm{bc}$ & $9.485 \mathrm{~b}$ & $8.73 \mathrm{~b}$ & 85.65 & 41.78 \\
\hline
\end{tabular}

Note: TSS, total soluble solids. Means within a column followed by the different letters are significantly different at P 0.05 level.

Table 6. Fruit quality employing different numbers of varieties of pollination bees.

Figure 10. Number of varieties of pollination bees employed and fruit-setting rate. 
When the ratio between the main variety of "Red Fuji" apples and pollination partners of "Qinguan" is 20:1, the fruit yield, fruit shape index, seed number, and deformity fruit rate of each tree employing 6, 12, and 18 varieties of bees are, respectively, shown in figure 10, table 7 , and table 8 . Notes: Means within a column followed by the same letter are not significantly different.

\begin{tabular}{llll}
\hline Number of bee varieties used (each tree) & $\begin{array}{l}\text { Average longitudinal } \\
\text { diameter }(\mathbf{m m})\end{array}$ & Average diameter $(\mathbf{m m})$ & Fruit shape index \\
\hline 6 & 66.41 & 75.26 & $0.9111 \pm 0.0103 \mathrm{a}$ \\
12 & 68.2 & 75.21 & $0.9076 \pm 0.0094 \mathrm{a}$ \\
18 & 67.65 & 74.28 & $0.8821 \pm 0.0121 \mathrm{a}$ \\
\hline
\end{tabular}

Table 7. Relation between number of varieties of pollination bees employed and fruit shape index.

\begin{tabular}{lllll}
\hline Number of bee varieties used (each tree) & $\begin{array}{l}\text { Total number } \\
\text { of seeds }\end{array}$ & Plump seed & Plumpness (\%) & $\begin{array}{l}\text { Irregular fruit } \\
\text { rate (\%) }\end{array}$ \\
\hline 6 & 140 & 134 & 95.7 & $56 \mathrm{a}$ \\
12 & 247 & 243 & 98.38 & $26 \mathrm{~b}$ \\
18 & 290 & 288 & 99.31 & $18 \mathrm{c}$ \\
\hline
\end{tabular}

Table 8. Relation between number of varieties of pollination bees and fruit seed number and irregular fruit rate.

In the absence of pollination partners the number of bee varieties used for pollination and the fruit-setting rate are shown in figure 11.

Figure 11. Fruit-setting rate of "Red Fuji" apple trees by bee pollination in the absence of pollination partners. 
The configuration of pollination partners is a major factor affecting the number of bee varieties to be used for pollination. A good configuration will allow employment of six varieties of pollination bees, enough to guarantee production requirements. If the configuration leads to insufficient pollination partners, it will be necessary to increase the number of varieties of bees to at least 12 for pollination purposes. In the absence of pollination partners, 16 varieties of bees will be needed to achieve a fruit-setting rate of $9.12 \%$.

\subsubsection{Scale of the pollination apiary}

The distance between buzzers and fruit trees had a significant effect on pollination. Foraging bees and fruiting percentage at different distances using 20 colonies are shown in tables 9 and 10.

\begin{tabular}{lllll}
\hline Distance (m) & Number of foraging bees & Flower number & Fruit number & $\begin{array}{l}\text { Fruiting } \\
\text { percentage }\end{array}$ \\
\hline $\mathbf{0}$ & 354 & 715 & 138 & 19.30 \\
$\mathbf{5 0}$ & 246 & 610 & 94 & 15.41 \\
$\mathbf{1 0 0}$ & 227 & 764 & 97 & 12.70 \\
$\mathbf{1 5 0}$ & 194 & 935 & 112 & 11.98 \\
$\mathbf{2 0 0}$ & 86 & 1,825 & 126 & 6.90 \\
\hline
\end{tabular}

Notes: 20-colony treatment involved setting up 5 survey spots, 1 every $50 \mathrm{~m}$ from the colony out to $300 \mathrm{~m}$. At every spot one apple tree of consistent variety, tree potential, on-year yield (high), and off-year yield (low) was selected. At every spot foraging bees were counted for 45 minutes and the fruiting percentage after 15 days was calculated.

Table 9. Number of foraging bees and fruiting percentage at different distances using 20 colonies in 2009.

\begin{tabular}{lllll}
\hline Distance $(\mathrm{m})$ & Flower number & Fruit number & Fruiting percentage & $\begin{array}{l}\text { Pollen amount } \\
\text { on stigma }\end{array}$ \\
\hline $\mathbf{0}$ & 1,723 & 286 & 16.6 & 6,050 \\
$\mathbf{5 0}$ & 1,843 & 304 & 16.49 & 5,450 \\
$\mathbf{1 0 0}$ & 3,090 & 417 & 13.5 & 6,889 \\
$\mathbf{1 5 0}$ & 1,738 & 228 & 13.12 & 5,850 \\
$\mathbf{2 0 0}$ & 1,790 & 202 & 11.28 & 6,050 \\
\hline
\end{tabular}

Table 10. Fruiting percentage at different distances using 20 colonies in 2010.

With increase of the distance between fruit trees and bee colonies the number of foraging bees gradually reduced. Bee pollination at a distance of $150 \mathrm{~m}$ between bee colonies and fruit trees was found to give the ideal fruiting percentage; therefore, the bee pollination effective radius was $150 \mathrm{~m}$ when 20 colonies are employed. 
With increase of the distance in the 0 to 200 -m range using 20 colonies the fruiting percentage decreased from 16.60 to $11.28 \%$; however, neither the trend nor change in the pollen count on the stigma were obvious. Despite there being more foraging bees and the fruiting percentage increasing with decrease in the distance from the colony within the 0 to 200-m range, 2010 was an off-year with low apple tree yield, reduced flower total quantity, and enlarged bee gather distance.

The number of foraging bees and fruiting percentage at different distances using 50 colonies are shown in tables $\mathbf{1 1}$ and $\mathbf{1 2}$.

\begin{tabular}{lllll}
\hline Distance $(\mathbf{m})$ & Number of foraging bees & Flower number & Fruit number & $\begin{array}{l}\text { Fruiting } \\
\text { percentage }\end{array}$ \\
\hline $\mathbf{0}$ & 907 & 1,070 & 339 & 31.68 \\
$\mathbf{5 0}$ & 593 & 1,775 & 236 & 13.30 \\
$\mathbf{1 0 0}$ & 600 & 1,250 & 140 & 11.20 \\
$\mathbf{1 5 0}$ & 342 & 1,865 & 208 & 11.15 \\
$\mathbf{2 0 0}$ & 262 & 1,400 & 148 & 10.57 \\
$\mathbf{2 5 0}$ & 241 & 1,255 & 70 & 5.58 \\
$\mathbf{3 0 0}$ & 189 & 1,580 & 97 & 6.14 \\
\hline
\end{tabular}

Notes: 50-colony treatment involved setting up 7 survey spots, 1 every $50 \mathrm{~m}$ from the colony out to $300 \mathrm{~m}$. At every spot one apple tree of consistent variety, tree potential, and on-year and off-year yields was selected. At every spot foraging bees were counted for 45 minutes and the fruiting percentage after 15 days was calculated.

Table 11. Foraging bees and fruiting percentage at different distances using 50 colonies in 2009.

\begin{tabular}{lllll}
\hline Distance (m) & Flower number & Fruit number & Fruiting percentage & $\begin{array}{c}\text { Pollen } \\
\text { amount }\end{array}$ \\
\hline $\mathbf{0}$ & 1,561 & 309 & 19.8 & 5,400 \\
$\mathbf{5 0}$ & 592 & 93 & 15.71 & 5,050 \\
$\mathbf{1 0 0}$ & 1,200 & 135 & 11.25 & 5,167 \\
$\mathbf{2 0 0}$ & 1,425 & 203 & 14.25 & 4,800 \\
$\mathbf{2 5 0}$ & 1,097 & 215 & 19.60 & 4,000 \\
$\mathbf{3 0 0}$ & 1,373 & 202 & 14.71 & 4,000 \\
\hline
\end{tabular}

Note: There were no 150-m data because tree vigor was poorer.

Table 12. Fruiting percentage at different distances using 50 colonies in 2010.

With increase of the distance in the 0 to $300-\mathrm{m}$ range using 50 colonies, in 2009 fruiting percentage decreased from 31.7 to $6.1 \%$, fruiting percentage at $200 \mathrm{~m}$ was $10.2 \%$, and fruiting 
percentage at $250 \mathrm{~m}$ was $5.6 \%$; therefore, the bee pollination effective radius was $200 \mathrm{~m}$ when 50 colonies are employed. In 2010, apple pollen counts on stigmas overall declined with increasing distance. This shows that foraging bees were fewer with increasing distance, yet fruiting percentage showed no significant change in trend.

The bee pollination effective radius was $150 \mathrm{~m}$ with 20 colonies and $200 \mathrm{~m}$ with 50 colonies. When apple trees gave on-year yields, production practice chose 50 colonies for bee pollination. When apple trees gave off-year yields the bee pollination effective radius was larger than apple trees in on-year yields and production practice chose 20 colonies for bee pollination.

\subsubsection{Technology behind getting bees to visit fruit trees}

The attraction of pollinators to some fruit trees is poor; one such is pear. When there are other plants such as rape, dandelion, and paulownia flowering near the target trees at the same time, foraging insects rarely alight on pear trees ${ }^{[29]}$. Artificially inducing bees to pollinate fruit trees when more desirable plants are available is a problem that must be solved. Many fruit trees bloom early in the year and flowering time is short; for example, apple trees flower for between 10 and 15 days and pear trees flower over a shorter period (about 7-10 days). Another technical difficulty is activating the foraging enthusiasm of the swarm.

In an effort to improve the foraging enthusiasm of bees, our team studied foraging behavior after using attractants. Apis mellifera 30 hives with six combs every hive had a consistent colony structure. The test involved 10 treatments and 3 colonies. Three treatments, respectively, used attractant I, II, and III, which our team prepared. Nine treatments involved feeding six compounds to bees: 1-mM methionine, 1-mM lysine, 1-mM arginine, 1-mM gallic acid, 500$\mu \mathrm{M} 8$-Br-cGMP, and pure syrup as a control treatment. Attractants were start-fed to Apis mellifera once every evening before the pear blossom appeared and then every 2 days until the end of the flowering. Pear flower load after sorting from total pollen was weighed, number of foraging bees on pear flowers were recorded, and percentage pear flower load and foraging bee number on pear flowers were calculated.

The weight of pear pollen load collected in a day is shown in figure 12. All treatments enhanced the foraging ability of bees for pear pollen. The foraging effect of hanging attractant I in hives $(77.56+1.59 \mathrm{~g} /$ group$)$ was significantly higher than other treatments. Those treatments that involved feeding the bees Arg $(62.05+/-2.01 \mathrm{~g})$, Lys $(62.2+2.3 \mathrm{~g}), 8$-Br-cGMP $(64.45+4.55 \mathrm{~g})$ and hanging attractant II in hives $(64.20+2.72 \mathrm{~g})$ were better than the control treatment $(49.11$ +1.03); other treatments showed no significant difference from the control treatment. 
Figure 12. Weight of pear pollen collected in a day.

Pear pollen was sorted from total pollen. The percentage of pear pollen in total pollen load collected in a day is shown in figure 13. The results show that treatment groups fed pear syrup and methionine showed no significant difference from the control group; the other seven groups were higher than the control group. Feeding lysine $(76.3 \%)$, hanging attractant $I$ in the hives $(79.3 \%)$, and hanging attractant II in the hives (80.2\%) were all significantly higher than other treatment groups $(P<0.05)$. Hanging attractant II in the hives was the most effective and had the highest percentage of pear pollen; hanging attractant I in hives coupled with the lysine groups was the next best.

Figure 13. Percentage of pear pollen in total pollen. 
Cameras were installed at the entrance to the hive, worker bees returning to the hive were recorded for 5 minutes every hour. The percentage of foraging bees on pear flowers out of total foraging bees is shown in figure 14. The results showed that treatment groups fed pear syrup, gallic acid, and methionine were significantly lower than the control group, whereas the group fed arginine and 8-Br-cGMP showed no significant difference from the control group. The groups fed lysine $(85.81 \%)$, hanging attractant I (86.74\%), attractant II $(87.27 \%)$, and attractant III $(85.67 \%)$ were significantly higher than the control group. The percentage of foraging bees improved by 3 to $4.5 \%$ after application of attractants I, II, and III.

Figure 14. Percentage of foraging bees on pear flowers out of total foraging bees.

The above results show that feeding bees lysine brings about the best effect of all the feeding treatments, increasing both the percentage of pear pollen load and the number of foraging bees on pear flowers. The effect of hanging attractant in the hives is better than feeding treatments. Hanging attractant II in the hives resulted in the highest percentage of pear pollen load, whereas hanging attractant I in the hives resulted in the highest weight of pear pollen. Both treatments can effectively increase foraging behavior.

\subsubsection{Technology underlying bees carrying pollinizer pollen}

Since some pear orchards have no pollinizers whatsoever, we developed a kind of bee-carrying powder device (figure 15). This device is installed at the entrance to the hive, fresh pollen is put in the upper part of the device, and pollen will leak out from the bottom when bees leave the hive. Bees that carry pollinizer pollen will pollinate leading cultivars. 


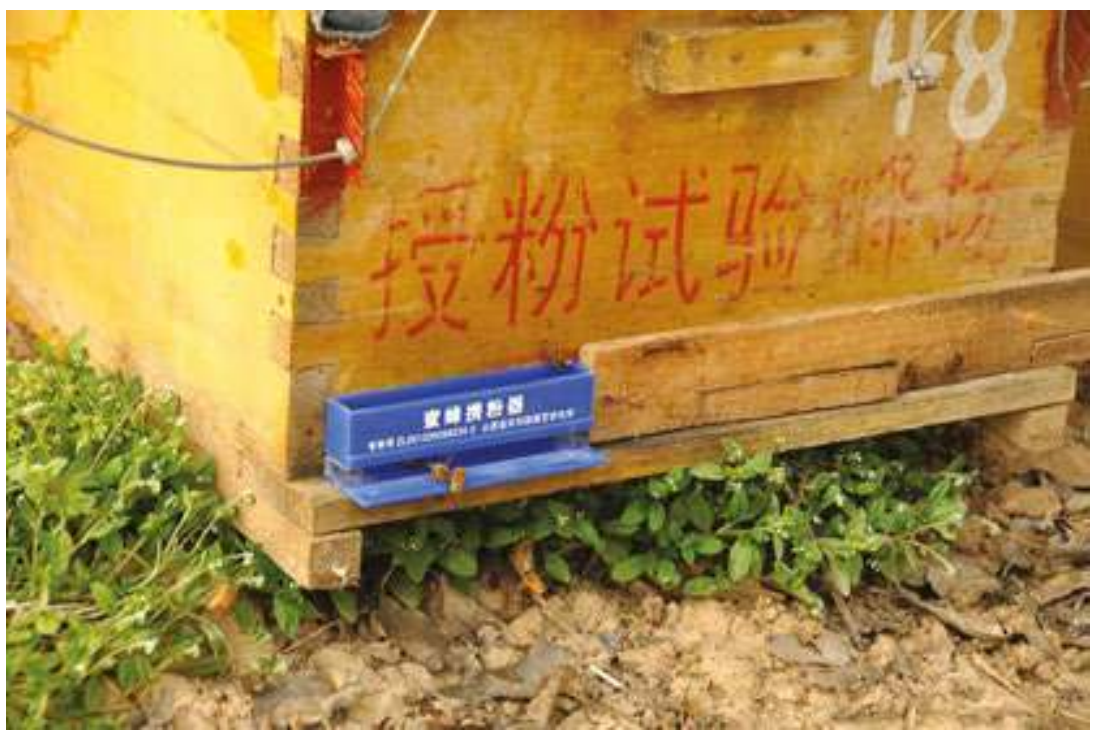

Figure 15. Device for bees to carry pollen.

\section{Industrialization of fruit tree pollination}

\subsection{Professional bee breeding for pollination}

Apis mellifera and Apis cerana cerana are the foremost pollination bees, primarily employed for the production of bee products (like honey), although they are sometimes used to pollinate fruit trees. However, they are not ideal pollination bees ${ }^{[30]}$. In the 1990s, researchers in China made a breakthrough in the artificial breeding of wild bumblebees, mastered the key technology to breed bumblebees indoors, domesticated six kinds of bumblebees, and established several production bases that could be gradually applied to facilities for orchard pollination $^{[31]}$. In an effort to fill the gap in agricultural practical development needs, researchers have bred and domesticated osmia bees, stingless bees, and andrenids in recent years. Our hope is that these technologies might play an important role in fruit tree pollination in years to come.

\subsection{Induced bee pollination technology: The need for further research}

Researchers have cultivated a special colony used exclusively for fruit tree pollination, developed a pollination technology that does not depend on a queen bee, and solved the beebutting-greenhouse problem in facilities crop. Although many advances have been made in bee pollination, There are remain many technical problems that must be solved such as how to get bees to visit fruit trees they do not favor or how to get the bees to improve pollination? Answers to these questions involve the study of the correlations between plants and bees, as 
well as the relationship between the spatial layout of fruit trees and the spatial distribution of foraging bees.

\subsection{Pollination professional development is slow}

At present, some areas in China have established bee pollination intermediary service agencies, bee industry cooperatives, pollination professional companies, and a few corresponding pollination intermediary services. However, these organizations have failed to provide the necessary market supply-and-demand information and technical training, or to set up a bee pollination service and relevant policies. There are a number of reasons for this: The scale of the industry in China is small, specialist companies are few in number, the degree of organization is low, and it is difficult to form a pollination network.

\section{Acknowledgements}

We are grateful to Professor Liu Fanglin from the Hefei Institute of Material Science, Chinese Academy of Sciences for modifying and improving the manuscript.

\section{Author details}

Guo Yuan*, Ma Weihua, Wu Wenqing and Song Huailei

*Address all correspondence to: yysgy3@163.com

Horticultural Institute, Shanxi Academy of Agricultural Sciences

\section{References}

[1] Zhang YX (Ed.) General fruit cultivation. Beijing: China Agriculture Press; 2014.

[2] State Statistics Bureau, (Ed.) Statistical year book of rural China in 2012. Beijing: Chinese statistics press; 2012.

[3] Available from: http://faostat.fao.org/browse/QQC/E

[4] Guo GN, Yan ZL, Zhang HT, et al. Current situation of production of early and mid season apple cultivars in China and progress in breeding for early and mid season apple cultivars. Journal of Fruit Science. 2009;26(6):871-877.

[5] Chen CG, Zhao DY, Xuan JH. The suggestion to apple varieties development in our country. Northern Fruits. 2015;xx(3):52-53. DOI: 10.16376/j.cnki.bfgs.2015.03.027 
[6] Ou XQ, Zhou Y. The analysis of concept of plants self-pollination and cross pollination. Biology report. 2007;42(11):23-25.

[7] Roubik DW. Pollination of cultivated plants in the tropics. FAO Agricultural Services Bulletin. 1995;118:1-196.

[8] Roubik DW (Ed.) Diversity in the real world: Tropical forests as pollinator reserves. In: Bees and the Environment (ed. Mardan M). Malaysia: South Bound Press; 1995.

[9] Shen JS, Wu WQ, Song HL, et al. The study of pollinating insects and their flowervisiting behavior on Malus pumila Mill. Journal of Environmental Entomology. 2015;37(4):720-725. DOI: 10. 3969 /j. issn. 1674-0858. 2015. 04. 4

[10] Lu YG, Qi WZ, Zhang SW, et al. Observational study on the insect visiting apple flowers in the central loess plateau petitions. Apiculture of China. 2012;63:27-29.

[11] Yang LL, Wu YR. The preliminary research on the kiwi pollinator. China apiculture. 1990;(3):2-4.

[12] Zhang YY, Wu WQ, Ma WH. The Investigation of Cherry Pollinator. Chinese Agricultural Science Bulletin. 2012;28(25):272-276.

[13] Li J, Zhu CD, Wang FH, et al. Current research on the status of wild bees and their pollination roles. Biodiversity Science. 2007;15(6):687-692. DOI: 10.1360/biodiv.070080

[14] Xie ZH, Xu HL, Yang P. Notes on monitoring, assessing and conserving pollinator biodiversity. Chinese Journal of Applied Entomology. 2011;48(3):746-752.

[15] Huang DY, Hao JS, Yu JF, et al. Impact of Human Activities on Pollination of Economic Crops. Nonwood Forest Research. 2008;26(4):114-120.

[16] Steffan-Dewenter I, Potts SG, Packer L. Pollinator diversity and crop pollination services are at risk. Trends in Ecology and Evolution. 2005;20:651.

[17] Kearns CA, Inouye DW, Waser NM. Endangered mutualisms: The conservation of plant-pollinator interactions. Annual Review of Ecology and Systematics. 1998;29:83112.

[18] Wu WQ, Guo Y, Shen JS, et al. Present situation investigation of bee pollination for pear. Apiculture of China. 2011;62:40-44.

[19] Li MH, Cong B, Li JP, et al. Mason Bee and Its Application on Fruit Tree Pollination. Journal of Jilin Agricultural University. 2004;26(4):422-425.

[20] Zhang GQ, Tian ZZ, Shen RM, et al. The effect of Apis mellifera pollination for Fuji and golden apple. Agricultural science technology and information. 2013;xx(1):23-25. DOI: 10.15979/j.cnki.cn62-1057/s.2013.01.025

[21] He WZ, Zhou WR. The effect of Osmia excavata Alfken, Apis mellifera and artificial pollination for apple. Apiculture of China. 2009;60(11):9-11. 
[22] Lou DL, Jiang FT, Wang SQ. Study on for [sic] Apple Bee Pollination. Apiculture of China. 2013;64:35-37.

[23] Zhang ZH, Yang PY, Li P, et al. The integrated application and demonstration effect of bee pollination and green early prevention and control production technology. China Plant Protection. 2015;35(4):43-45.

[24] Yuan F, Wei YP, Zhang YL. Research on the result of pollination of apple by Osmia bees. Acta Agriculturae Boreali-occidentalis Sinica. 1992;1(3):93-96.

[25] Liu JL, Cui LX, Le WQ. The pollination effect of Osmia excavata Alfken for different varieties of pear tree. Hebei Fruits. 2014;xx(1):44 -45.

[26] Guo Y, Shao YQ, Ma WH, et al. Study on Physiological Activity and Pollination Characteristic of Stigma and Pollen of 'Dangshansuli'. Chinese Agricultural Science Bulletin. 2013;29(16):110 -114.

[27] Dong J, An JD, Huang JX, et al. Effects of pollination by different bees on peach fruit development and quality under greenhouse conditions. Chinese Journal of EcoAgriculture. 2011;19(4):836-842.

[28] $\mathrm{Mu} \mathrm{HJ}$, Sun $\mathrm{ZP}$, Zhang SH, et al. The test of bumblebee pollination for facilities fruit trees. Hebei Fruits. 2006;xx(6):6-7.

[29] Teng TZ, Huo YG, Li Y. The relationship of pear fertilization and bee pollination. Apiculture of China. 2011;ZA:19-21.

[30] Peng WJ, Wu J, An JD, et al. Comparative studies on pollination biologies of Bombus lucorum and Apis mellifera ligustica in Katy apricot greenhouse. Journal of Fujian Agriculture and Forestry University (Natural Science Edition). 2007;36(3):302-306.

[31] Wu J, Shao YQ (Eds.) Wonderful efficient crop production technology-honeybee pollination. Beijing: China Agriculture Press; 2011. 